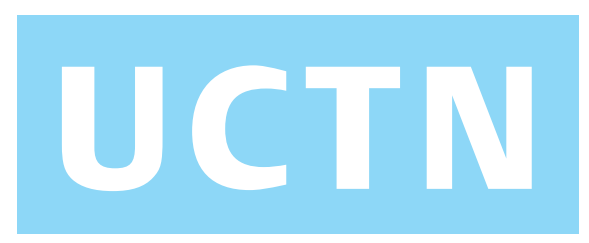

\title{
Post-insertion tailoring of plastic biliary stents: A novel technique
}

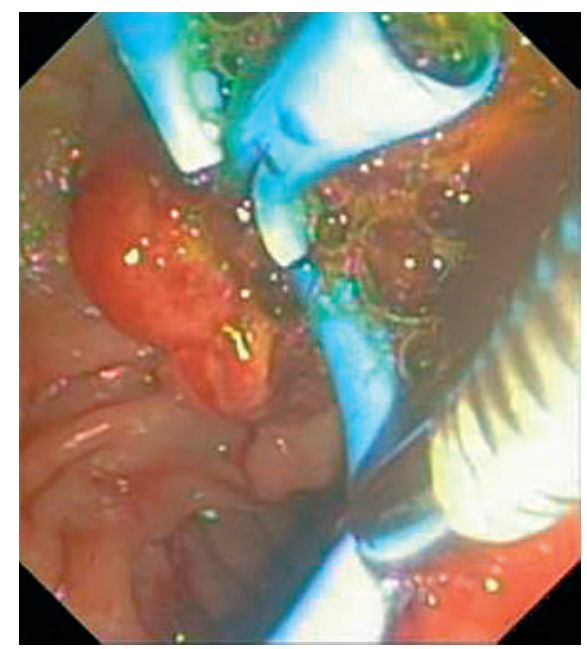

Figure 1 The stent is grasped using the lithotriptor sheath-polypectomy snare device.

Although the insertion of multiple plastic biliary stents is a well established procedure, it can be technically difficult, particularly when proximal benign common bile duct or malignant hilar strictures must be negotiated [1]. When multiple stents are placed, it is therefore not uncommon for one or more stents to protrude markedly into the lumen of the duodenum. When faced with this situation the endoscopist has three options: to remove the protruding stent, with the risk of displacing one or more stents already in place; to attempt to reposition the stent using grasping forceps; or, finally, to leave the protruding stent in situ, which has a small associated risk of trauma to the duodenum [2] or of stent occlusion. It is well known that metal biliary or duodenal stents can be trimmed [3-5]; however, there are no available published data on tailoring plastic biliary devices.

We have developed a simple technique for shortening plastic biliary stents in situ, thereby avoiding the problems described above. The metal sheath of the mechanical lithotriptor (Innoflex IGL 1957M, $7 \mathrm{Fr}$, $165 \mathrm{~cm}$ ) is loaded with the wire from a polypectomy snare loop from which the outer plastic sheath has been stripped. This device is then inserted through the working channel of the duodenoscope and the stent is grasped, using the snare loop, at

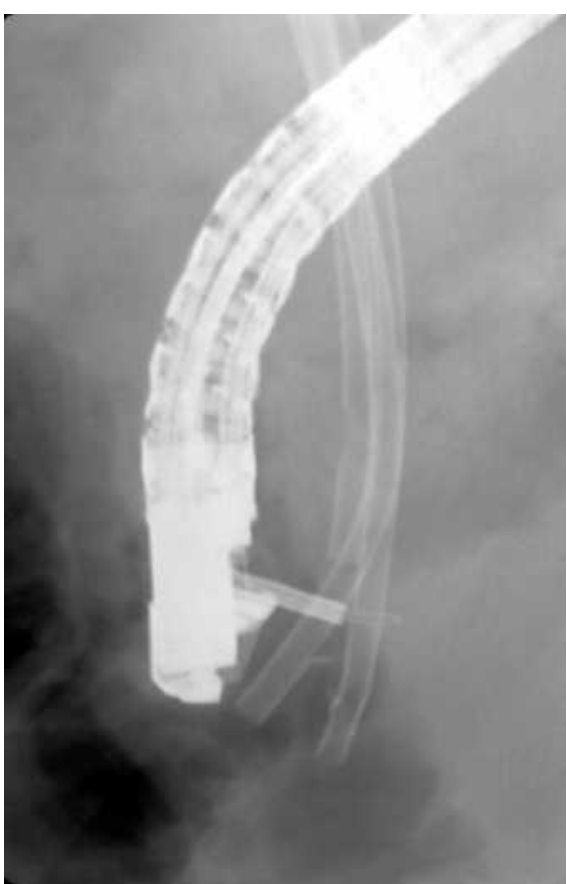

Figure 2 Radiography shows the lithotriptor sheath, with the wire loop of the polypectomy snare around the plastic stent.

the desired trimming point (Figure $\mathbf{1}$ and 2). The free end of the polypectomy snare wire is then attached to the lithotriptor rotator and force applied in a manner similar to when crushing a stone, with the desired effect of cutting through the plastic stent. The diameter of the trimmed stent(s) is only slightly affected (Figure $\mathbf{3}$ ), and at the same time the position of the inserted stents can be maintained until subsequent stent exchanges. Thus far, we have used this technique for more than 15 plastic biliary stents without any complications.

\section{Endoscopy_UCTN_Code_TTT_1AR_2AZ}

\section{Mutignani, S. Dokas, V. Perri,}

\section{A. Tringali, G. Costamagna}

Digestive Endoscopy Unit, University

Hospital A. Gemelli, Catholic University, Rome, Italy.

\section{References}

${ }^{1}$ Costamagna G, Pandolfi M, Mutignani $\mathrm{M}$ et al. Long-term results of endoscopic manage-

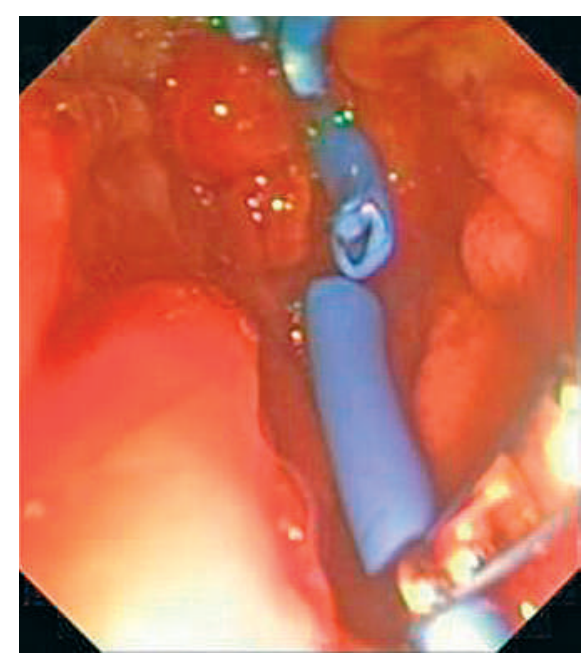

Figure 3 End result after trimming of the stent. The lumen of the stent is only slightly reduced, and the fragment of the plastic stent is grasped with a foreign-body forceps to be removed along with the endoscope.

ment of postoperative bile duct strictures with increasing numbers of stents. Gastrointest Endosc 2001; 54: 162 - 168

2 Roses LL, Ramirez AG, Seco AL et al. Clip closure of a duodenal perforation secondary to a biliary stent. Gastrointest Endosc 2000; 51: $487-489$

${ }^{3}$ Shaver CP, Brady P, Pinkas H. You don't have to retrieve to relieve: how and when to trim a self-expanding metal biliary stent. Endoscopy 2004; 36: 833

${ }^{4}$ Matsushita M, Takakuwa H, Matsubayashi Y, Okazaki K. Distally migrated and impacted biliary metallic stents: removal versus trimming. Endoscopy 2005; 37: 677

${ }^{5}$ Vanbiervliet G, Piche T, Caroli-Bosc FX et al. Endoscopic argon plasma trimming of biliary and gastrointestinal metallic stents. Endoscopy 2005; 37: 434-438

\section{Correspondling Author}

\section{Mutignani, M.D.}

Digestive Endoscopy Unit

University Hospital A. Gemelli

Largo A

Gemelli 8

00168 Rome

Italy

Fax: +39-06-30156581

E-mail: massimiliano.mutignani@rm. unicatt.it 